\title{
Pendekatan bidang ortodontik-periodontik pada perawatan migrasi gigi patologis
}

\author{
Aulia Damayanti ${ }^{*}$, Shafira Kurnia ${ }^{1}$ \\ ${ }^{1}$ Departemen Periodonsia, Fakultas Kedokteran Gigi Universitas Airlangga, Indonesia
}

*Korespondensi: aulia16damayanti@gmail.com

Submisi: 13 Juli 2020; Penerimaan: 28 November 2020; Publikasi online: 30 November 2020

DOI: $10.24198 / \mathrm{ikg} . \mathrm{v} 32 \mathrm{i} 2.28568$

\begin{abstract}
ABSTRAK
Pendahuluan: Periodontal abses dapat menyebabkan migrasi gigi patologis (ekstrusi) dan defek intraoseus. Pada kondisi ini perawatan ortodontik-periodontik merupakan pendekatan terapeutik yang dapat memposisikan kembali gigi yang telah mengalami migrasi patologis dan memperbaiki kondisi periodontal. Terapi multidisiplin sangat penting dalam praktik kedokteran gigi untuk mencapai hasil yang optimal. Tujuan laporan kasus ini adalah untuk menggambarkan pendekatan bidang ortodontik-periodontik pada perawatan migrasi gigi patologis. Laporan kasus: Laki-laki, 35 tahun dengan keluhan utama gigi inisisivus kanan atas abses, goyang, dan nyeri. Secara klinis pada gigi 11 terdapat kegoyangan derajat tiga, poket periodontal bagian mesial $7 \mathrm{~mm}$, resesi $3 \mathrm{~mm}$, dan kontak prematur pada gigi 41. Pemeriksaan radiologi terlihat kerusakan tulang yang parah. Penatalaksanaan kasus, pada kunjungan pertama, pemberian medikasi oral sebagai terapi darurat, kunjungan kedua adalah scaling dan root planing, occlusal adjustment, dan splinting pada kunjungan ketiga. Kemudian pemasangan ortodontik cekat pada rahang atas dilakukan pada kunjungan berikutnya, untuk mengembalikan posisi gigi insisivus lateral yang ekstrusi. Setelah mencapai posisi yang sesuai, dilakukan bone graft pada gigi. dapat mengembalikan posisi gigi yang mengalami ekstrusi, mengurangi kegoyangan gigi dan mengembalikan fungsi estetik pasien. Simpulan: pendekatan bidang ortodontik-periodontik pada perawatan migrasi gigi patologis menunjukkan keberhasilan setelah kontrol enam bulan pasca bedah ditandai dengan gambaran panoramik adanya penambahan densitas serta tinggi tulang yang signifikan pada daerah defek, gigi insisivus sentral atas kembali ke posisi normal dan kepuasan pasien tercapai.
\end{abstract}

Kata kunci: Bone graft, migrasi gigi patologis, bidang ortodontik-periodontik, periodontal abses

\section{The orthodontic-periodontic approach for the treatment of pathologic tooth migration}

\section{ABSTRACT}

Introduction: Periodontal abscess can cause pathologic tooth migration (extrusion) and intraosseous defect. In this condition, orthodontic-periodontic treatment is a therapeutic approach to performed teeth repositions after pathological migration thus improving the periodontal condition. Multidisciplinary therapy is essential in dental practice to achieve optimal results. This case report was aimed to describe the orthodontic-periodontic approach for the treatment of pathologic tooth migration. Case report: A 35-years-old male with the chief complaint of abscess, loose, and painful right maxillary incisor. In the tooth 11 was clinically found a third-degree wobble, $7 \mathrm{~mm}$ mesial periodontal pocket, $3 \mathrm{~mm}$ recession, and premature contact in tooth 41. Radiology examination revealed severe bone damage. At the first visit, the oral medication was administered as an emergency therapy; the second visit, the scaling and root planning and occlusal adjustment were performed; and splinting was performed at the third visit. The orthodontic placement of the maxilla was installed at the next visit, to reposition the extruded lateral incisors. After reaching the appropriate position, the bone graft was performed to restore the extruded tooth position, reduce tooth instability, and restore the patient's aesthetical function. Conclusion: The orthodontic-periodontic approach for the treatment of pathologic tooth migration showed success after six months of postoperative control, characterised by a panoramic image of a significant increase in bone density and height in the defect area, the maxillary central incisor returned to its normal position; thus the patient's satisfaction was achieved.

Keywords: Bone graft, pathologic tooth migration, orthodontic-periodontic approach, periodontal abscess. 


\section{PENDAHULUAN}

Periodontitis adalah penyakit periodontal yang paling umum dijumpai dan mengenai $>50 \%$ populasi dewasa di seluruh dunia..$^{1,2}$ Periodontitis kronis merupakan inflamasi kronis yang mengakibatkan peradangan di dalam jaringan pendukung gigi, dan kehilangan perlekatan periodontal, serta tulang secara progresif. Definisi ini menguraikan karakteristik klinis dan etiologi utama dari penyakit ini: (1) pembentukan plak mikroba, (2) peradangan periodontal, dan (3) kehilangan perlekatan periodontal dan tulang alveolar. ${ }^{1,2,3}$

Trauma oklusi adalah salah satu faktor yang dapat memperparah periodontitis kronis. Trauma oklusi didefinisikan sebagai kerusakan pada perlekatan periodontal sebagai hasil beban oklusi yang berlebihan, sehingga menyebabkan rasa sakit atau ketidaknyamanan. Trauma oklusi dapat disebabkan oleh perubahan kekuatan oklusal dan atau berkurangnya kapasitas periodonsium untuk menahan kekuatan oklusal. $^{3}$ Trauma oklusi primer terjadi jika terdapat peningkatan kekuatan dan durasi dari tekanan oklusal yang berlebihan pada jaringan periodonsium normal atau sehat. Contoh penyebab trauma oklusi primer antara lain restorasi yang terlalu tinggi. Trauma oklusi sekunder terjadi ketika tekanan oklusal normal yang diterima menjadi berlebihan karena telah kehilangan jaringan yang parah atau berkurangnya kemampuan jaringan periodonsium untuk menahan tekanan oklusal. ${ }^{4}$ Ciri-ciri trauma oklusi sekunder antara lain kegoyangan gigi yang berlebihan (mobility dinamis), terutama pada gigi yang foto rontgennya menunjukkan adanya pelebaran ligamen periodontal; defek tulang lebih sering berbentuk angular; terdapat poket infraboni; disertai adanya migrasi patologis. ${ }^{3,4}$

Migrasi gigi patologis dapat diartikan sebagai perubahan posisi gigi (pergeseran gigi) yang terjadi akibat terganggunya keseimbangan antara faktor-faktor yang mempertahankan posisi gigi fisiologis oleh adanya penyakit periodontal. ${ }^{5}$ Prevalensi migrasi gigi patologis pada pasien dengan penyakit periodontal telah dilaporkan berkisar dari 30,03-55,8\%. ${ }^{6}$ Karakteristik migrasi gigi patologis antara lain ditandai dengan adanya diastema, ekstrusi gigi, rotasi dan labioversi (facial flaring) dan adanya pergeseran gigi yang memperparah kerusakan jaringan periodontal, sehingga menimbulkan masalah estetik bagi pasien. ${ }^{5,6}$ Migrasi patologis dari gigi anterior merupakan masalah estetik dan fungsional yang berkaitan dengan penyakit periodontal tahap lanjut, yang berdampak pada pasien baik secara sosial maupun secara psikologis, dan menjadi dorongan pasien untuk mencari perawatan gigi. ${ }^{7}$

Etiologi migrasi gigi patologis multifaktorial antara lain kehilangan perlekatan periodontal; tekanan yang dihasilkan dari jaringan inflamatori pada poket periodontal; faktor oklusal seperti hilangnya gigitan posterior, maloklusi klas II, interferensi oklusal, gabungan gaya anterior, pola pengunyahan fungsional protrusif, bruxism, lengkung rahang yang memendek; tekanan dari jaringan lunak seperti lidah, bibir, pipi dan frenulum labial; hiperplasia gingiva yang diinduksi oleh obatobatan seperti fenitoin, siklosporin dan calcium channel blocker; gaya erupsi; kebiasaan seperti menghisap bibir, menjulurkan lidah, menggigit kuku jari, menghisap jari, merokok dan memainkan instrumen tiup. Namun, literatur mengatakan bahwa destruksi struktur pendukung gigi merupakan faktor yang paling relevan berkaitan dengan migrasi patologis. ${ }^{8,9,10}$

Periodontitis kronis menyebabkan kerusakan tulang lebih dari $50 \%$ di area sekitar giginya. Berdasarkan pemeriksaan radiologi dapat diketahui bahwa penyebab utama dari migrasi gigi patologis ini adalah kerusakan tulang. Kim et al, ${ }^{11}$ pada tahun 2012 mengamati bahwa tidak ada faktor tunggal yang dikaitkan dengan migrasi gigi patologis, namun faktor primer adalah kehilangan tulang. Penelitian oleh Rohatgi et $a l,{ }^{12}$ yang juga mempelajari etiologi dari migrasi gigi patologis, dan menyimpulkan bahwa adanya hubungan langsung antara migrasi gigi patologis dengan kehilangan perlekatan klinis serta inflamasi gingiva. ${ }^{12}$

Pemilihan metode untuk melakukan perawatan terhadap kasus migrasi gigi patologis biasanya berdasarkan pendekatan multidisiplin. Kasus ringan dengan diastema pada gigi anterior $2 \mathrm{~mm}$ akibat periodontitis cukup dilakukan perawatan periodontal saja, seperti skeling root planing dan bedah flap. Kasus moderate dengan gigi ekstrusi dan sakit pada gigi dilakukan perawatan periodontal dan ortodontik (tekanan intrusi ringan). Kasus parah dengan diastema pada gigi anterior $\geq 2 \mathrm{~mm}$ akibat periodontitis dilakukan dengan perawatan prostodontik (ekstraksi dan 
Ada banyak faktor dari diri pasien sendiri untuk memutuskan perawatan terbaik pada kelainan migrasi gigi patologis. Faktor tersebut meliputi kooperatif pasien, motivasi untuk mempertahankan gigi alami, faktor skeletal, faktor ekonomi, avaibilitas perawatan, kesehatan sistemik, dan menerima perawatan bedah periodontal, apabila diperlukan..$^{6,12}$ Laporan kasus ini meliputi perawatan bidang ortodontik-periodontik dalam mengatasi permasalahan migrasi patologis pada gigi insisivus sentral rahang atas. Intrusi secara ortodontik dapat mengubah kerusakan tulang horizontal menjadi lebih dalam dan sempit, sehingga tulang akan lebih mudah menerima perawatan untuk regenerasi jaringan periodontal melalui prosedur grafting.

Pasien dengan penyakit periodontal berisiko mengalami kerusakan periodontal di masa depan. Bila kekuatan ortodontik dilakukan dalam batas biologis, tidak akan menyebabkan hilangnya perlekatan jaringan ikat dan terjadinya pembentukan poket periodontal. Perawatan periodontal untuk menghilangkan plak harus dilakukan sebelum memulai perawatan ortodontik. Pemeliharaan kebersihan mulut yang sangat baik selama perawatan sangat penting untuk menentukan keberhasilan seluruh perawatan. ${ }^{13}$
Perawatan multidisiplin sebagai bagian integral dari praktik kedokteran gigi, sangat penting untuk memenuhi tuntutan dari perkembangan estetika dari pasien. ${ }^{13}$ Tujuan laporan kasus ini adalah untuk menggambarkan pendekatan bidang ortodontik-periodontik pada perawatan migrasi gigi patologis.

\section{LAPORAN KASUS}

Pasien laki-laki usia 35 tahun datang ke Rumah Sakit Gigi dan Mulut Universitas Airlangga mengeluhkan gigi depan rahang atas sakit, goyang dan memanjang kebawah serta mengeluarkan nanah. Berdasarkan anamnesis diketahui pasien tidak memiliki penyakit sistemik, alergi, dan tidak merokok. Pemeriksaan ekstra oral tidak terdapat kelainan. Pemeriksaan intra oral terlihat kebersihan mulut buruk, terdapat fistula pada bagian labial gigi 11, kemerahan dengan supurasi positif (Gambar 1).

Pemeriksaan periodontal ditemukan poket dengan kedalaman $7 \mathrm{~mm}$ pada mesial gigi 11 disertai dengan kegoyangan derajat tiga serta resesi $4 \mathrm{~mm}$ bagian labial (Gambar 2). Hasil tes vitalitas pulpa positif (nilai 6/10), pemeriksaan oklusi dan artikulasi menunjukkan gigitan terbuka.

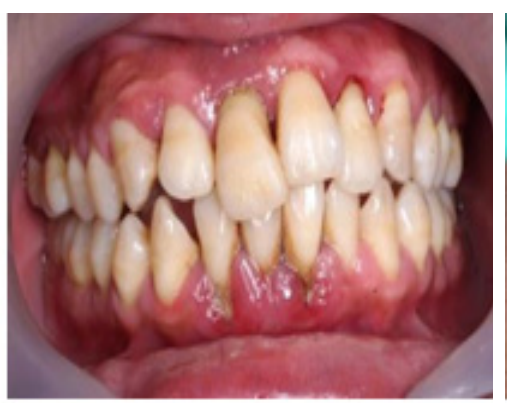

Gambar 1. (A) Foto klinis intra oral pasien sebelum perawatan (tampak depan); (B) oklusal rahang atas; (C) oklusal rahang

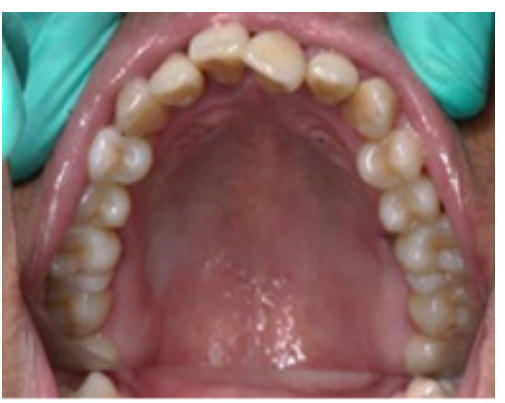

Gambar 1. (A) Foto klinis intra oral pasien sebelum perawatan (tampak depan); (B) oklusal rahang atas; (C) oklusal rahang

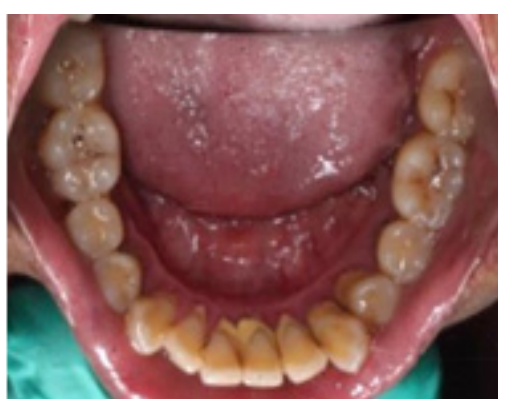

Gambar 1. (A) Foto klinis intra oral pasien sebelum perawatan (tampak depan); (B) oklusal rahang atas; (C) oklusal rahang bawah.(Sumber: Dokumentasi pribadi)

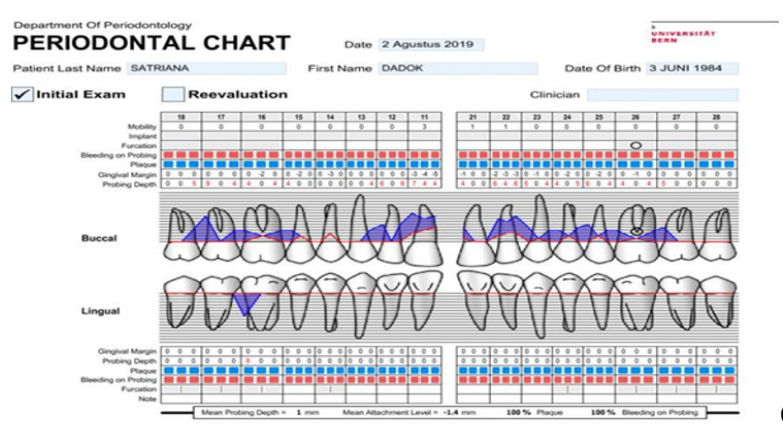

A

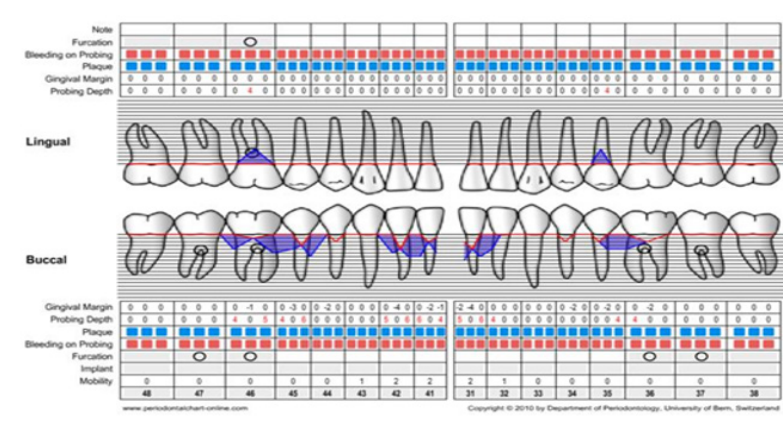

B

Gambar 2. Periodontal chart pasien sebelum perawatan rahang atas (A) pada gigi 11 terdapat poket periodontal $7 \mathrm{~mm}$ disertai kegoyangan derajat tiga; pada rahang bawah (B) kedalaman poket parah dan kegoyangan pada gigi-gigi anterior.

(Sumber: Dokumentasi pribadi) 
Pemeriksaan radiografis menunjukkan adanya resorpsi tulang alveolar di daerah lateral gigi 11 mencapai ujung apeks (Gambar 3A).

Diagnosis klinis adalah abses periodontal gigi 11. Prognosis baik karena pasien mempunyai motivasi yang tinggi dan sangat kooperatif. Etiologi kelainan ini yaitu adanya bakteri plak dan oklusi traumatik pada gigi 41 dan gigi 11 .

Kunjungan pertama pasien diberikan penjelasan serta menandatangani informed consent, kemudian dilakukan terapi inisial seperti medikamentosa, intruksi kebersihan mulut, skeling dan root planing. Tujuan dari fase inisial adalah untuk mengeliminasi etiologi mikroba, eliminasi peradangan serta faktor-faktor yang memperberat penyakit periodontal. ${ }^{3}$ Setelah itu dilakukan recall untuk melihat respon penyakit terhadap fase inisial.

Tindakan selanjutnya pada pasien ini dengan melakukan occlusal adjustment untuk penyelerasan kontak oklusal kemudian pemasangan splinting dari gigi 23-33 bagian palatal untuk immobilisasi terhadap kegoyangan gigi. Kontrol satu minggu pasien tidak ada keluhan sakit, merasa lebih nyaman dan gigi tidak goyang.

Pemasangan splinting pada kasus ini menggunakan fiber karena memiliki beberapa keuntungan yaitu mudah pemeliharaan, bebas logam, transparan, estetik, memberikan kenyamanan pasien serta memudahkan dalam pembersihan. ${ }^{14}$ Saat pasien recall terakhir diketahui bahwa kedalam poket $6 \mathrm{~mm}$ pada bagian mesial gigi 11, gambaran hasil rontgen tampak kerusakan tulang mencapai $1 / 3$ tengah akar disertai adanya ekstrusi gigi 11. Sebelum pasien direncanakan untuk dilakukan pembedahan bone graft, dilakukan perawatan ortodontik secara komprehensif untuk memposisikan kembali gigi 11 yang mengalami ekstrusi tersebut.
Setelah dilakukan perawatan periodontal konvensional, dilanjutkan dengan pemasangan alat ortodonti cekat pada rahang atas untuk mengintrusi gigi insisivus sentral, memakai breket roth ukuran 0,20 dan diawali dengan menggunakan kawat $\mathrm{NiTi}$ 0,12 namun fiber splint pada bagian palatal gigi 11 dilepas terlebih dahulu (Gambar 4A). Pemasangan ortodonti cekat selama kurang lebih dua bulan menunjukkan hasil signifikan pada gigi 11 yang menempati posisi gigi semestinya (Gambar 4B). Ortodonti cekat dilepas dan dipasang kembali fiber splint sebagai retensi ortodontik mencegah relapsnya susunan gigi. Tahapan selanjutnya dilakukan perawatan periodontal bone graft terhadap gigi 11

Kunjungan selanjutnya dilakukan bone graft di area gigi 12, 11, 21, dan 22. Tekanan darah pada saat dilakukan flap adalah 120/80 mmHg. Flap periodontal dilakukan dibawah anestesi infiltrasi anterior rahang atas. Insisi sulkular dimulai dari daerah midlabial 13 hingga mesial 23 dengan blade no.15c, dilakukan elevasi flap menggunakan periosteal (Gambar 5A). Flap dicoba dikembalikan dan dilakukan undermining flap agar tidak terdapat tarikan saat penutupan. Setelah elevasi flap, kalkulus subgingiva, jaringan granulasi dan sementum nekrotik dibersihkan menggunakan skeler dan kuret gracey hingga permukaan akar terasa halus dan tampak bersih (Gambar 5B). Setelah jaringan granulasi bersih, terlihat resorbsi tulang alveolar yang sangat dalam di gigi 11 pada bagian labial. Tulang alveolar di lingual masih tinggi dan adekuat. Irigasi dilakukan dengan menggunakan saline steril.

Daerah defek tulang ditutup dengan bone graft dan membran pericardium (Gambar 6A). Flap dikembalikan dan dijahit menggunakan benang nylon 5,0 jarum $3 / 8$, round, dan penutupan daerah

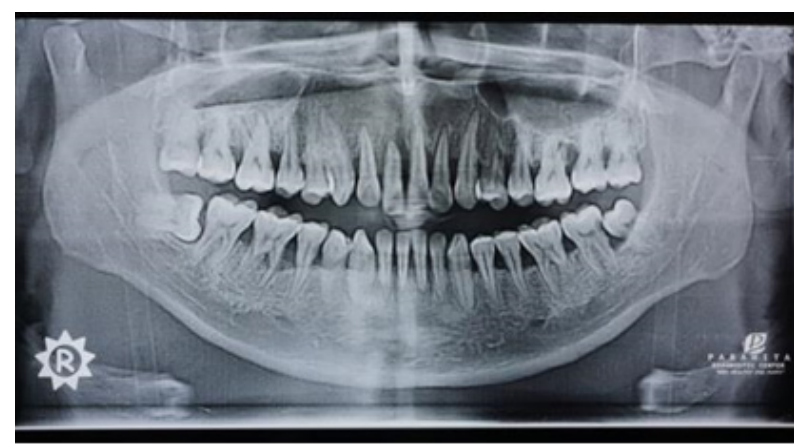

A

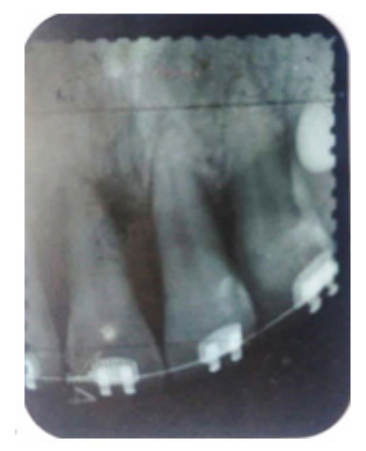

Gambar 3. (A) Radiografi panoramik pasien sebelum perawatan; (B) Radiografi periapikal gigi 11 setelah 2 bulan pemasangan ortodonti cekat.(Sumber: Dokumentasi pribadi). 

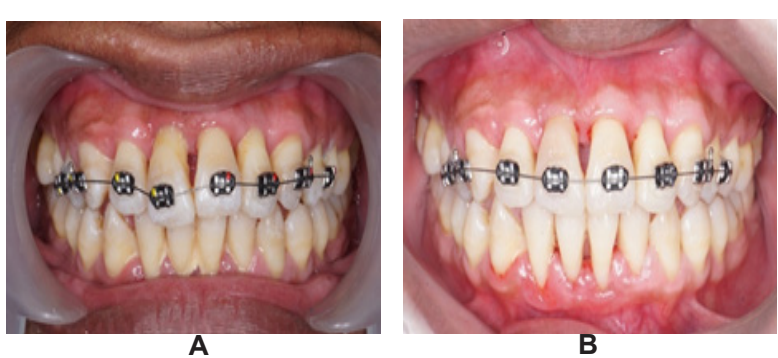

Gambar 4. (A) Pemasangan alat ortodonti cekat rahang atas; (B) 2 bulan setelah pemasangan, tercipta gigi yang aligning (Dokumentasi pribadi).
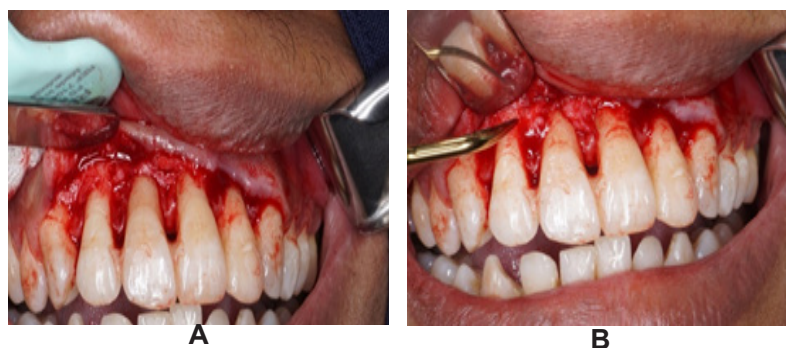

Gambar 5. (A) Elevasi flap menggunakan periosteal,terlihat defek tulang vertical; (B) pembersihan jaringan granulasi dengan skaler dan kuret gracey (Dokumentasi pribadi).
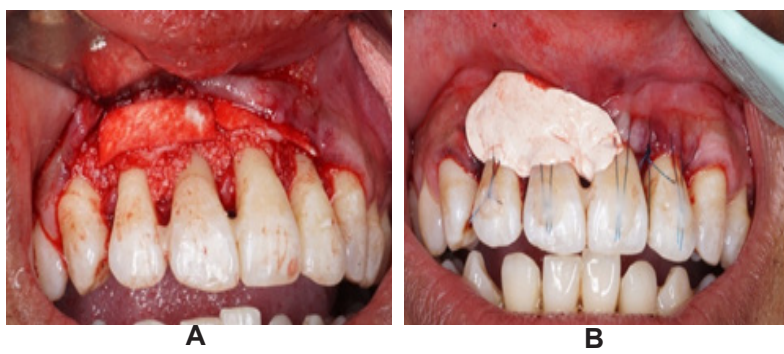

Gambar 6. (A) Defek tulang ditutup dengan bone graft dan membran pericardium; (B) penutupan daerah operasi dengan periodontal pack (Dokumentasi pribadi)
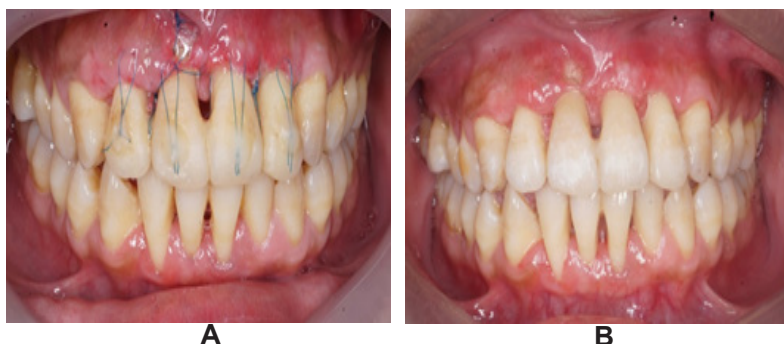

Gambar 7. Kontrol pascabedah periodontal (A) 1 minggu, pelepasan periodontal pack; (B) 2 minggu, pelepasan jahitan (Dokumentasi pribadi)

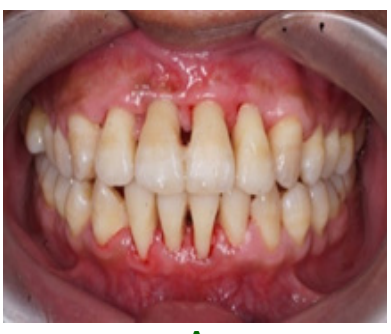

A

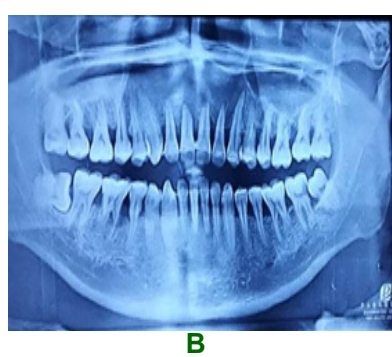

B
Gambar 8. Foto klinis kontrol 3 bulan pascabedah (A), radiografi panoramik setelah 6 bulan bedah (B) (Dokumentasi pribadi) operasi dengan periodontal pack (Gambar 6B). Medikasi per oral pascabedah berupa antibiotik (amoxisillin 500mg 3x1 hari), dan analgesik (asam mefenamat $500 \mathrm{mg} 3 \times 1$ hari). Kontrol 1 minggu pascabedah dilakukan pelepasan periodontal pack dan pasien tidak menunjukkan adanya keluhan subjektif, nyeri, supurasi dan bengkak namun terdapat hiperemi didaerah marginal gingiva (Gambar 7A). Pelepasan jahitan dilakukan pada kontrol dua minggu pascabedah setelah tidak terdapat keluhan subjektif, hiperemi, supurasi dan oedema (Gambar 7B).

Kontrol tiga bulan pascabedah, secara klinis tidak ada keluhan subjektif dari pasien, hiperemi, oedema dan supurasi negatif (Gambar $8 \mathrm{~A}$ ). Rontgen panoramik pada bulan keenam pascabedah tampak adanya penambahan densitas serta tinggi tulang yang signifikan pada daerah defek (Gambar 8B).

Kasus ini menggabungkan perawatan ortodontik dengan gerakan intrusi, terapi non periodontal, serta bone graft sebagai cara untuk meregenerasi periodonsium yang hilang dalam kasus migrasi gigi insisivus sentral pada pasien dengan penyakit periodontal lanjut dan kehilangan tulang alveolar yang parah.

\section{PEMBAHASAN}

Migrasi patologis gigi anterior adalah kasus yang sering dijumpai di klinik dan merupakan masalah di bidang estetik dan fungsi. Dalam bidang periodontal keadaan ini merupakan pertanda suatu kelainan periodontal lanjut, yang dapat melibatkan gigi rahang atas ataupun rahang bawah. Kerusakan tulang dan jaringan penyangga gigi yang terjadi dapat melibatkan satu atau beberapa gigi, karenanya kecermatan dalam pemeriksaan harus dilakukan. ${ }^{15}$ Perawatan yang biasa dilakukan adalah dengan melakukan intrusi, untuk menggerakan gigi ke koronal. Beberapa peneliti menyebutkan bahwa pergerakan ini dapat mengembalikan kerusakan tulang yang telah terjadi.

Penelitian secara klinis dan histologis menunjukkan kemungkinan untuk terjadinya attachment yang baru, mengembalikan estetik dan fungsi pada pergerakan intrusi gigi. ${ }^{16}$ Tindakan intrusi secara ortodontik dapat meningkatkan sirkulasi suplai darah baru ke daerah defek dan 
dapat mengubah defek tulang yang awalnya horizontal menjadi defek tulang dengan dinding vertikal. ${ }^{17}$ Dinding bertulang vertikal ini akan menampung bahan graft dan menyediakan sumber yang baik dari sel-sel mesenchymal yang dapat berdiferensiasi menjadi sel-sel yang berguna, seperti osteoblas dan fibroblas, selama proses regenerasi jaringan periodontal. ${ }^{17,18}$ Oleh karena itu, kami telah memilih perawatan dimulai dengan intrusi ortodontik dilanjutkan oleh bedah periodontal regeneratif sejalan dengan penelitian oleh Ramachandra ${ }^{19}$ yang menerangkan hubungan erat antara perawatan ortodontik dan kesehatan periodontal dapat memberikan hasil yang signifikan pada pasien.

Menurut Ismail bahwa pemakaian alat ortodontik berhasil dalam mengatasi migrasi gigi patologis yang diakibatkan adanya kerusakan tulang. ${ }^{20}$ Proses intrusi gigi akan berhasil dengan baik selama tekanan ringan dan pemeliharaan oral hygiene yang tepat. ${ }^{18,19}$ Pergerakan gigi diinduksi oleh tekanan ortodontik, dimana tekanan yang diberikan menyebabkan remodeling pada gigi dan jaringan periodontal. Tekanan ortodontik dihasilkan dari kompresi tulang alveolar dan ligamen periodontal pada satu sisi, dan regangan ligamen periodontal pada sisi yang berlawanan. Tulang secara selektif diresorbsi pada sisi kompresi dan mengalami deposisi pada sisi regangan. ${ }^{14}$

Perawatan ortodontik didasarkan pada premis bahwa ketika kekuatan diterapkan pada gigi, ia ditransmisikan ke jaringan yang berdekatan, dan terjadi perubahan struktur tertentu dalam jaringan, yang memungkinkan pergerakan gigi. Kasus pada pasien ini pergerakan gigi berupa intrusi dengan tekanan ringan (5-15gram). ${ }^{14,21}$ Tekanan ortodontik ringan (tekanan kurang dari tekanan pembuluh darah) akan menyebabkan iskemia pada ligamen periodontal, yang simultan dengan pembentukan tulang dan resorpsi. Sehingga menyebabkan pergerakan gigi secara kontinu. ${ }^{14}$

Kontrol tiga bulan pascabedah flap dengan bone graft, ditemukan penyembuhan baik, poket periodontal berkurang menjadi $3 \mathrm{~mm}$, resesi $2 \mathrm{~mm}$ dan tidak ada kondisi peradangan. Dan selama ini pasien selalu dianjurkan untuk menjaga kebersihan mulutnya. Kontrol saat 6 bulan pascabedah, tampak adanya penambahan densitas dan tinggi tulang yang signifikan secara radiografis. Sejalan dengan penelitian El-Attar yang memperlihatkan peningkatan secara signifikan indeks plak, dan densitas tulang setelah intrusi ortodontik dan dilanjutkan dengan bedah regeneratif dengan bone graft. ${ }^{16}$ Perawatan selanjutnya merupakan perawatan estetik untuk resesi gingiva dengan gingival graft. Namun pasien menolak dikarenakan permasalahan biaya, sehingga alternatif perawatan estetika lainnya dengan pembuatan gingival mask.

\section{SIMPULAN}

Pendekatan bidang ortodontik-periodontik pada perawatan migrasi gigi patologis menunjukkan keberhasilan setelah kontrol enam bulan pasca bedah ditandai dengan gambaran panoramik adanya penambahan densitas serta tinggi tulang yang signifikan pada daerah defek, gigi insisivus sentral atas kembali ke posisi normal dan kepuasan pasien tercapai.

\section{DAFTAR PUSTAKA}

1. Jin LJ, Lamster IB, Greenspan JS, Pitts NB, Scully C, Warnakulasuriya S. Global burden of oral diseases: emerging concepts, management and interplay with systemic health. Oral Dis 2015;22:609-19. DOI: 10.1111/ odi.12428.

2. Carranza FA. Periodontal response to external forces. In: Newman MG, Takei HH, Klokkevold PR, Carranza FA, editors. Carranza's Clinical Periodontology $12^{\text {th }}$ ed.2018. p. 300-8.

3. Azodo CC, Erhabor P. Management of tooth mobility in the periodontology clinic: An overview and experience from a tertiary healthcare setting. Afr J Med Health Sci 2016;15:50-7. DOI: $10.4103 / 2384-5589.183893$

4. Rangari R, Reddy C. Etiology of pathological tooth migration related to periodontal diseases- $A$ comprehensive review. International Journal of Current Research.2016;8 (8):36362-4

5. Khatri JM, Jadhav MM, Tated GH. OrthoPerio Synergy-A Review.Modern Reasearch in Dentistry.2018;1(4):65-72. DOI: 10.31031/ MRD.2018.01.000518

6. Moka L, Boyapati1 R, Salavadhi SS, Chintalapani S, Maloth KN, Nagubandi K. Determinants of pathological tooth migration. Journal of Dr. NTR University of Health Sciences.2018;7:89-93. DOI: 10.4103/ 
JDRNTRUHS.JDRNTRUHS 5217

8. Kumar $N$, Jhingta $P$, Negi $K S$, Bhardwaj VK, Sharma D, Thakur AS. Combined periodontal-orthodontic treatment of pathologic tooth migration: A case study with 10-year follow-up. Contemporary Clinical Dentistry.2018;9(2):S377-81. DOI: $10.4103 /$ ccd.ccd $480 \quad 18$

9. Rath SK, Datan SK, Gupta A. Case Report: Ortho perio Management of Malocclusion in an Adult Patient.Journal Interdisciplinary Dentistry. 2017; 7(1): 41-44. DOI: 10.4103/jid. iid $81 \quad 15$

10. Pinho T, Coutinho-alves C, Neves M. Management of Pathological Tooth Migration in Patients with Advanced Periodontal Disease. 2013; 67(9): 520-528

11. Kim YI, Kim MJ, Choi JI, Park SB. A multidisciplinary approach for the management of pathologic tooth migration in a patient with moderately advanced periodontal disease. International J periodon Restor Dent. 2012; 32: 225-30.

12. Rohatgi S, Narula SC, Sharma RK, Tewari S, Bansal P. Clinical evaluation of correction of pathologic migration with periodontal therapy. Quintessence International. 2011; 42(1): 2230.

13. Suwandi T. Keterkaitan antara bidang orthodonti dan periodonti dalam perawatan estetika rongga mulut. Jurnal Kedokteran Gigi Terpadu.2020; 2(1): 68-74

14. Suwandi T. Perawatan awal penutupan diastema gigi goyang pada penderita periodontitis kronis dewasa. J PDGI. 2010; 59(3): 105-9
15. Oh SL. An interdisciplinary treatment to manage pathologic tooth migration: A clinical report, The Journal of Prosthetic Dentistry. 2011; 106(3): 153-8

16. El-Attar H, El-Kadi, Rabie, Ezz-el-Arab, Salah N, Bedair. Evaluation of the Combined Orthodontic-Periodontal Therapy in the Management of Extruded Anterior Teeth in Patients with Aggressive Periodontitis. International Journal of Health Sciences \& Research. 2019; 9(12): 25-38.

17. Cao T, Xu L, Shi J, Zhou Y. Combined orthodontic-periodontal treatment in periodontal patients with anteriorly displaced incisors.American Journal of Orthodontics Dentofacial Orthopedics. 2015; 148(5): 80513.DOI: 10.1016/j.ajodo.2015.05.026.

18. Panwar M, Jayan B, Arora V, Singh S. Orthodontic management of dentition in patients with periodontally compromised dentition. J Indian Soc Periodontol. 2014;18(2): 200-204. DOI: 10.4103/0972-124X.131325.

19. Ramachandra CS, Shetty PC, Rege S, Shah C. Ortho-periointegratedapproachinperiodontally compromised patients. J Indi Soc Periodontol. 2011; 15(4): 414-7. DOI: 10.4103/0972124X.92583.

20. Ismail A. Penatalaksanaan Ekstrusi Gigi Incisivus Lateral pada Kasus Pathologic Tooth Migration Periodontitis Kronis dengan Menggunakan Splint Fixed Appliance.Odonto Dental Journal. 2015; 2(2): 22-4.

21. Kapoor $P$, Kapoor $D$, Kapoor U. Challenges in Ortho-Perio Interaction-A Systemic Update. Journal of Dentistry and Oral Care. 2017; 3(2): 1-2. DOI: $\underline{10.15436 / 2379-1705.17 .1427}$ 